\title{
Burnout on Employees Organizational Commitment: Five Star Hotel Employees
}

\section{Derya KARA}

a Ankara Hacı Bayram Veli University, Faculty of Economics and Administrative Sciences, Ankara, Turkey. deryakara@gazi.edu.tr

\begin{tabular}{|c|c|}
\hline ARTICLE INFO & ABSTRACT \\
\hline Keywords: & Purpose - The purpose of this study is to examine the effects of burnout on employees' \\
\hline Burnout & organizational commitment in five-star hotels, in Turkey. \\
\hline Organizational Commitment & Design/methodology/approach - The study was conducted on 443 employees: 323 males and \\
\hline Employee & 120 females. The study composed of two analyses. First, the relationship between employee \\
\hline Five Star Hotels & $\begin{array}{l}\text { organizational commitment and burnout was investigated using Pearson Product-Moment } \\
\text { Correlation Coefficient. Second, Multiple Linear Regression was applied in order to test } \\
\text { organizational commitment as a function of three dimensions of burnout. }\end{array}$ \\
\hline Received 1 January 2019 & Findings - According to the Pearson Product-Moment Correlation Coefficient findings, \\
\hline Revised 10 March 2019 & emotional exhaustion has a positive effect on employees' organizational commitment and but \\
\hline Accepted 15 March 2019 & $\begin{array}{l}\text { not statistically significant. On the other hand, personal accomplishment and depersonalization } \\
\text { is negatively related to organizational commitment and statistically significant. Moreover, with }\end{array}$ \\
\hline Article Classification: & $\begin{array}{l}\text { Multiple Linear Regression analysis, dimensions of employee burnout were found to be } \\
\text { significant predictors of organizational commitment. }\end{array}$ \\
\hline Research Article & $\begin{array}{l}\text { Discussion -The findings of the study potentially affect hotel employees by identifying the } \\
\text { effects of burnout on employees' organizational commitment in five-star hotels, in Turkey. This } \\
\text { study provides meaningful implications for the hospitality industry in terms of burnout and } \\
\text { organizational commitment. }\end{array}$ \\
\hline
\end{tabular}

\section{Introduction}

The growing internationalization of the hospitality industry means that today's managers may find themselves working in almost any area of the world. In each country cultural, political and legislative factors influence the workplace, and managers need to understand these if they are to organize and motivate the workforce to best effect (Burrell et al., 1997). For a country to be successful in the tourism and hospitality industry it needs a talented, skilled and committed workforce at all levels, from those providing front-line service to customers and clients as well as women and men at various levels of supervision and management (Koyuncu et al., 2008). In a global service economy the workplace is changing. With a tremendous increase in the service sector, decreasing labour pools and increasing demands for services, quality of work life has to be taken seriously by employers. Desire for a good quality of work life has led to increased interest in employee organizational commitment (Smith et al., 1996). On the other hand, burnout is associated with decreased job satisfaction and a reduced commitment to the job or the organisation (Maslach et al., 2001). There is an evident need to clarify organizational commitment, how this variable is related to burnout. The question of the study whether emotional exhaustion, personal accomplishment and depersonalization have a negative effect on employees' organizational commitment in the context of hotel employees in Turkey. Therefore, the overall objective of this study is to understand how burnout effects on employees organizational commitment using a large sample size by focusing on Turkish hospitality sector. This study offers a new perspective on the effect of burnout on employees organizational commitment.

\section{Conceptual Development}

\subsection{Burnout}

Burnout is a prolonged response to chronic emotional and interpersonal stressors on the job, and is defined by the three dimensions of exhaustion, personal accomplishment (also known as personal efficacy in the 
literature), and depersonalization (as also known as cynicism in the literature). "Exhaustion" represents the basic individual stress dimension of burnout. It refers to feelings of being overextended and depleted of one's emotional and physical resources (Maslach et al., 2001). Employees who are emotionally exhausted typically feel as though they lack adaptive resources and cannot give any more to their job. The energy that they once had to devote to their work is now depleted, leaving them without the resources to perform their work (Halbesleben and Buckley, 2004). "Personal Accomplishment" represents the self-evaluation dimension of burnout. It refers to feelings of incompetence and a lack of achievement and productivity at work (Maslach et al., 2001). Employees perceive that they cannot perform as well at their job as they once could (Halbesleben and Buckley, 2004). It is characterized by a tendency to evaluate oneself negatively. Frequently there is the perception of a lack of progress or even lost ground (Ledgerwood et al., 1998). "Depersonalization" represents the interpersonal context dimension of burnout. It refers to a negative, callous, or excessively detached response to various aspects of the job (Maslach et al., 2001). It is marked by the treatment of customers as objects rather than people and cynicism towards co-workers, customers, and the organization (Ledgerwood et al., 1998).

Many individuals begin their careers with expectations that they will be able to make great contributions to their employer and society. After a year or two on the job, they begin to realize they are not living up to these expectations. Many systemic reasons may contribute to the gap that exists between a new employee's goals including (1) unrealistically high expectations because of a lack of exposure to the job during training, (2) constraints placed on the worker by organizational policies and procedures, (3) inadequate resources to perform one's job, (4) co-workers who are frequently uncooperative and occasionally rebellious, and (5) a lack of feedback about one's successes (Jackson and Schuler, 1982). Maslach and Jackson (1981) claimed that burnout seems to be correlated with various self-reported indices of personal distress, including physical exhaustion, insomnia, increased use of alcohol and drugs, and marital and family problems. Kuruuzum et al. (2008) reported that burnout has various consequences in the hospitality industry. For example, the turnover rate is at least twice as great in service industries (25-30 per cent) as compared with non-service industries (815 per cent). Lee and Shin (2005) investigated the psychological dimensions such as job burnout, engagement and exhaustion. They found that turnover intention was positively correlated with workload, exhaustion, and cynicism. The study done by Chiang and Liu (2017) showed that room attendants who suffer job stress do have higher job burnout, which, in turn, affects turnover intentions. Another study done by Yavas et al. (2011) put forth that burnout influences extra-role performance deleteriously and exacerbates quitting intentions in the hotel industry in Turkey. Jung et al. (2012) showed a positive relationship between employees' perceptions of role stress and burnout in a deluxe hotel. Participants who report a high level of burnout are more likely to leave position. Moreover, burnout is also extremely costly for organizations with estimates from $\$ 500$ to $\$ 10,000$ per person in the hotel industry depending upon the level of the position (Perrewé et al., 1991). Since burnout has important and costly ramifications for organizations and individuals, it is important that management have a clear and accurate understanding of the construct as well as an understanding of the factors and conditions that contribute to burn-out (Ledgerwood et al., 1998).

\subsection{Organizational Commitment}

Organizational commitment has grown in popularity in the literature of organizational psychology and organizational behavior. The concept has received a great deal of empirical study both as a consequence and an antecedent of other work-related variables of interest (Mathieu and Zajac, 1990). Commitment has been consistently identified as an important variable in understanding the work behavior of employees in organizations (Hau-siu Chow, 1994). Mowday et al. (1979) defined commitment as a strong belief in, and acceptance of, the organization's goals and values; willingness to exert considerable effort on behalf of the organization; and a strong desire to maintain membership in the organization.

The concept of organizational commitment refers to a person's affective reactions to characteristics of his/her employing organization. It is concerned with feelings of attachment to the goals and values of the organization, one's role in relation to this, and attachment to the organization for its own sake rather than for its strictly instrumental value. As a positive outcome of the quality of work experience, the concept can be regarded as a factor contributing to subjective well-being at work (Cook and Wall, 1980). Job/role characteristics and work experiences may be most important characteristics in encouraging organizational commitment (Maxwell and Steele, 2003). Organizational commitment has also been viewed as a dimension 
of organization effectiveness which contributes to increased effectiveness through work performance and reducing turnover (Loke, 2001). Fulford (2005) studied justice, job satisfaction, and organizational commitment among hotel employees and found that organizational commitment has been shown to be significantly negatively related to employee turnover. Researchers have found that organizational commitment translate to behaviors likely to increase customer satisfaction. Highly committed employees "go the extra mile", extending their work efforts beyond job requirements, for example (Casal, 1996). Aven et al. (1993) reported that committed employees contribute to the organization in positive ways innovation at a lower cost) than less committed workers.

\subsection{The Effects of Burnout on Organizational Commitment}

Burnout comprises emotional experiences and cognitive components. If an individual is not passionate for his or her job, has poor interpersonal relationships at work, and cannot find a sense of self-worth from performing his or her job, then the person will not experience happiness in his or her work (Peng et al., 2013). Building on the work of Humborstad et al. (2007) suggested that burnout reduces staff's willingness to deliver quality services and that this effect is moderated by individual staff's level of affective organizational commitment. Positive contact with a supervisor might involve praise, guidance, and promotions, while positive contact with a coworker might refer more to friendship, help, and comfort. It is conceivable that these different types of positive contact would have different relationships to burnout and commitment, and that a similar argument could be made with regard to negative contacts (Leiter and Maslach, 1988).

Organizational commitment and its relationships with various situational characteristics have been studied by the researchers. Organizational commitment without doubt has been shown to be related to turnover (e.g., Koch and Steers, 1978; Mowday et al., 1979; Angle and Perry, 1981; Wagner, 2007), absenteeism (e.g., Koch and Steers, 1978; Mowday et al., 1979), job satisfaction (e.g., Bateman and Strasser, 1984; Maslach et al., 2001; Yousef, 2002). Moreover, there have been a significant number of studies about organizational commitment and burnout levels of employees. For example, Jackson et al., (1987) suggested that each burnout component is significantly related to organizational commitment and high levels of burnout would be associated with reduced commitment among public service lawyers. Peng et al. (2013) found that organizational commitment was significantly correlated to job burnout. Leiter and Maslach (1988) studied the impact of interpersonal environment on burnout and organizational commitment and findings showed that burnout leads to reduction in organizational commitment. Lee and Ashforth (1996) determined that burnout dimensions were related to organizational commitment. Kim et al. (2013) studied workplace incivility, empowerment, burnout, and organizational commitment of hospital nurses and their findings showed that the variables affecting organizational commitment were direct effect of burnout. Another study by Gemlik et al. (2010) investigated the relationship between burnout and organizational commitment among health sector staff in Turkey and found a significant relationship between burnout and organizational commitment. Burnout typically has been assumed to be a predictor of organizational commitment. The study by Kalliath et al. (1998) confirmed that organizational commitment had both direct and indirect effects on burnout. In the sample of nurses, greater commitment to the organization had a direct effect on reduced levels of emotional exhaustion and depersonalization, and an indirect effect on depersonalization via exhaustion. Salehi and Gholtash (2011) examined the relationship between job satisfaction, job burnout and organizational commitment with the organizational citizenship behavior among members of faculty and their findings showed that job burnout has a negative influence on the organizational commitment. Moreover, Liang (2012) investigated the relationships among work values, burnout, and organizational citizenship behaviors of hotel front-line service employees. Findings showed that burnout is important factors to consider for promoting organizational citizenship behaviors. Relating to the examined literature, although the relationship between burnout and organizational commitment literature is very rich, it has seen that there is very limited research on this topic in the case of the hospitality sector. Thus, the goal of this study is to examine the effects of the burnout on employees organizational commitment in the context of hotel employees in Turkey. The overall model of the study with associated hypotheses is shown in Figure 1. 


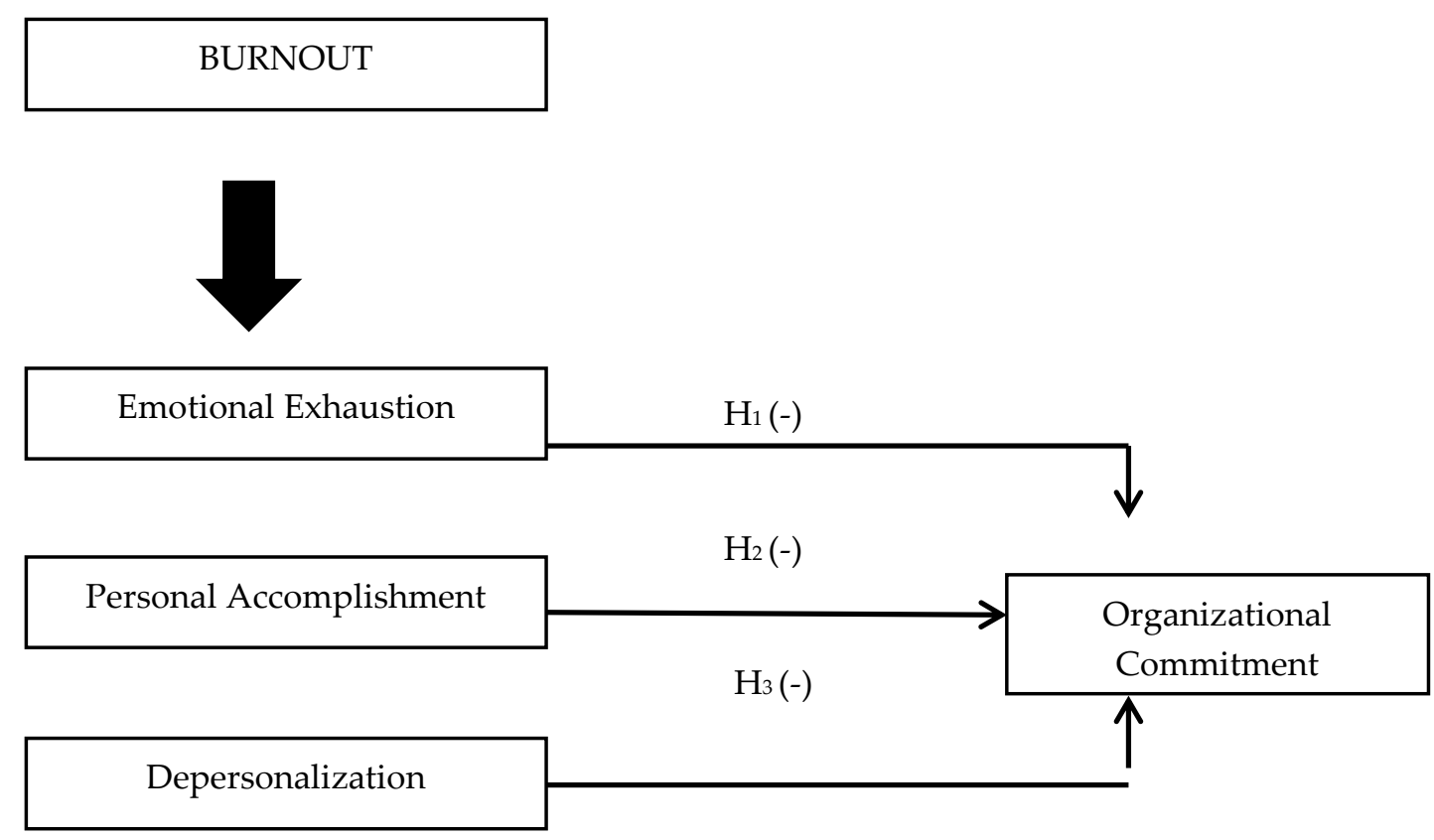

Figure 1. The overall model of the research

Employee organizational commitment is hypothesized in the context of hospitality employees to be affected by dimensions of burnout in this study (see Figure.1). Following this explanation, this particular study proposes the following three hypotheses:

$\mathrm{H}_{1}$ : Emotional exhaustion has a significant negative effect on employees' organizational commitment.

$\mathrm{H}_{2}$ : Personal accomplishment has a negative effect on employees' organizational commitment.

$\mathrm{H}_{3}$ : Depersonalization has a negative effect on employees' organizational commitment.

\section{Methodology}

\subsection{Data and Sampling}

The data was collected during the months of June 2010 through October 2010 from 5-star hotel employees in Turkey. 5- star hotels chosen because these hotels have a larger number of employees allowing us to populate the sample with "enough" employees. These hotels also meet the rating requirements of five stars as specified by the Ministry of Culture and Tourism. The study used a proportional stratified random sampling based on the number of 5-star hotels and total number of employees. According to the survey "Hotel and Tourism Industry Labor Force Survey" conducted by the Turkish Ministry of Culture and Tourism (1989), the number of staff per bed is 0.59 in 5-star hotel establishments. Moreover, according to data obtained from the Turkish Ministry of Culture and Tourism (2009), the total number of beds in the certified tourism business is 209.471 in Turkey. Based on this information, the total survey population is estimated by multiplying the number of beds by the number of staff per bed, which resulted in 123.587 . This figure (123.587) was treated as the limit of the universe and following the sample size calculation as suggested by Yamane (2001), the appropriate sample size turned out to be 384 . Initially, based on the size of the hotel, an appropriate number of questionnaires were sent to each hotel manager to distribute the questionnaire. In total, around 1200 questionnaires were distributed and after a waiting period of 5 months, 443 usable questionnaires were generated which provided a response rate of almost $37 \%$.

The sample consists of employees who worked in all departments of the hotels that were covered in the study. This sampling scheme also met the acceptable level of sample size that was suggested for the study. To ensure confidentiality and anonymity, the hotel employees were instructed not to identify themselves in the questionnaire, and asked to return the completed questionnaire in a box located in a place accessible to all employees. To prevent potential language problems, the questionnaire was translated into Turkish using back translation method by the research team. 
The study composed of three parts. The first part of the survey comprises some statements about demographic characteristics of employees (gender, marital status, age, education, monthly income level, departments, length of time in organization and tourism sector). The second part, employee burnout was captured using three dimensions developed by Maslach \& Jackson (1981). Emotional exhaustion (coefficient Alpha is 0,82) has 9 items (e.g., "I feel emotionally drained from my work"), personal accomplishment (coefficient Alpha is 0,90 ) has 8 items (e.g., "I can easily understand how my recipients feel about things") and depersonalization (coefficient Alpha is 0,76) has 5 items (e.g., "I feel I treat some colleagues as if they were impersonal objects"). Responses were captured using 5-point Likert scales ranging from "I do not agree at all" (1) to "I agree completely" (5). The third part of the study was measured organizational commitment using a 15 items scale developed by Mowday et al. (1979). Example items include "I am willing to put in a great deal of effort beyond that normally expected in order to help (name of the organization) be successful," "I talk up (name of the organization) to my friends as a great organization to work for," "I feel very little loyalty to (name of organization)" (reverse coded). One composite value was used for statistical analysis because of the measure is considered unidimensional. The Cronbach's Alpha for the complete instrument was .88, which is deemed acceptable Responses to these items were captured using 5-point Likert scales with the end-points labeled with "I do not agree at all" (1) and "I agree completely" (5).

\subsection{Analysis of data}

Of the 443 participants for whom data were analyzed, gender distribution was rather skewed towards female participants $(72.9 \%$ male and $27.1 \%$ female, respectively), reflecting the current situation of the sector in the selected hotel types in Turkey. The respondents were mainly single (61.2\%), 27-42 years old (50.6\%). 47.9\% employees had some high school degree, $65.0 \%$ earning a monthly income of 2500 Turkish Lira and less, $47.9 \%$ working in the organization and $42.4 \%$ working in the tourism sector for $1-5$ years. The distribution of work departments was rather even; $11.7 \%$ front office, $10.2 \%$ accounting, $20.8 \%$ housekeeping, $14.9 \%$ food and beverage, $13.1 \%$ human resources, $7.7 \%$ sales and marketing, $10.4 \%$ public relations, and $8.6 \%$ other departments.

The correlations, means, and standard deviations of the study constructs are shown in Table 1.

Table 1. Means, standard deviations, and correlations among constructs $(N=443)$

\begin{tabular}{lllllll}
\hline Variables & M & SD & 1 & 2 & 3 & 4 \\
\hline 1. Emotional Exhaustion & 2.6950 & .83641 & - & & & \\
2. Personal Accomplishment & 3.1764 & $\mathbf{9 6 . 0 5 0}$ & $.120^{*}$ & - & & \\
3. Depersonalization & 2.5043 & .84385 & $.427^{* *}$ & $.269^{* *}$ & - & \\
4. Organizational Commitment & 3.4352 & .74969 & .014 & $-.157^{* *}$ & $-.176^{* *}$ & - \\
\hline
\end{tabular}

Note: $p^{*}<.05, p^{* *}<.01$

Initially, the relationship between employee organizational commitment and burnout was investigated using Pearson Product-Moment Correlation Coefficient. Preliminary analyses were performed to ensure no violation of the assumptions of normality, linearity and homoscedasticity. According to the findings, there is a positive correlation between employees organizational commitment and emotional exhaustion but not statistically significant $(\mathrm{r}=.014)$. Moreover, there is a negative, moderate level of correlation between employee organizational commitment and personal accomplishment $(\mathrm{r}=-.157, \mathrm{p}<.01)$ and depersonalization $(\mathrm{r}=-.176, \mathrm{p}<.01)$. As seen from the results of correlational analysis, high levels of the burnout associated with lower levels of organizational commitment.

Furthermore, Multiple Linear Regression was applied in order to test organizational commitment as a function of three dimensions of burnout and reveal the relative importance of burnout dimensions in explaining organizational commitment in the context of the five star hotels in Turkey (Table 2). 
Table 2. The multiple linear regression analysis regarding the correlation between employees organizational commitment and burnout

\begin{tabular}{lllllll}
\hline Independent Variables & $\mathbf{B j}$ & $\mathbf{S}(\mathbf{b j})$ & $\mathbf{T}$ & $\mathbf{p}$ & $\left(R^{2)}\right.$ & Sig. \\
\hline Constant & 3.888 & .160 & 24.271 & .000 & .054 & $\mathrm{~F}=8.340$ \\
Emotional Exhaustion & .099 & .046 & 2.152 & .032 & $\mathrm{p}=.000$ \\
Personal Accomplishment & -.093 & .038 & -2.467 & .014 & \\
Depersonalization & -.170 & .047 & -3.612 & .000 & & \\
\hline
\end{tabular}

Note: $\mathrm{B} \mathbf{j}=$ Unstandardized coefficients, $\mathrm{S}(\mathrm{bj})=$ Standard errors

The overall model was found to be significant $(\mathrm{F}=8.340, \mathrm{p}<0.001)$, which indicates that at least one regression coefficient, obtained from the multiple linear regression model, is different from 0 , which is a clear sign of the fact that there is a correlation between the variables. As seen Table2, the multiple determination of coefficient $\left(R^{2)}\right.$ is .054 . This result showed that .05 percent of the total variance in employee organizational commitment stems from the independent variables (burnout dimensions). An examination of standardized beta coefficients reveals that depersonalization exerts the highest negative influence on organizational commitment (beta=-.191), followed by personal accomplished (-.119). On the other hand, emotional exhaustion had a positive sign with a significant beta value of .110 in the context of this study.

\section{Conclusion}

This study was conducted to determine the effects of burnout on employees' organizational commitment. The study results can provide (a) some guidance in improving employees' organizational commitment levels and (b) global and regional implications for the hospitality and tourism sector. To determine the effects of burnout on employees' organizational commitment; Maslach Burnout Inventory (MBI) and Organizational Commitment Scale were used in this study.

In this study, the relationship between employee organizational commitment and burnout was investigated using correlation analysis. Contrary to $\mathrm{H} 1$ hypothesis, the result demonstrates that emotional exhaustion has a positive sign but was not significant. However, in the regression analysis the relationship was significant. Moreover, the relationship between personal accomplishment and organizational commitment is negative and significant. H2 supported. Finally, depersonalization is negatively related with organizational commitment and significant. H3 supported.

Consistent with this study results, diminished personal accomplishment and depersonalization have a significant negative effect on organizational commitment. The findings support previous literature (HolletHaudebert et al., 2011) suggested that depersonalization is negatively related to organizational commitment. Leiter and Maslach (1988) suggested that all three dimensions of burnout were significantly correlated with organizational commitment. Burnout leads to reduced organizational commitment. Moreover, Jung and Kim (2012) found that as a result of burnout, employees reported diminished commitment to the organization. Maslach et al. (2001) determined negative effects of burnout on organizations such as high turnover rate, decrease performance and job satisfaction. Moreover, they claimed that burnout is reduced commitment to the job or the organization. Participation in decision making may help prevent burnout by clarifying role expectations and giving employees an opportunity to reduce some of their role conflicts (Jackson and Schuler, 1982).

Second, multiple linear regression was applied in order to analyze the relation between employee organizational commitment and burnout dimensions. With this analysis, employees' organizational commitment and burnout dimensions (emotional exhaustion, personal accomplishment, and depersonalization) were found to be significant $(\mathrm{F}=8,340, \mathrm{p}<0.001)$. Organizational commitment is essential for retaining and attracting well qualified workers as only satisfied and committed workers will be willing to 
continue their association with the organization and make considerable effort toward achieving its goals. An employee's positive attitude toward his/her job engenders greater commitment toward the organization (Nagar, 2012).

The main implication of this study is clear. When organizational commitment of employees is enhanced, they will have positive behaviors towards their organizations. Moreover, they don't want to go from organizations and the rate of turnover will decrease. Because of the increasing need for qualified employees, it is imperative that managers in the hospitality industry be aware of the causes and effects of burnout. They can minimize burnout for all levels of management. The results of this study might be used as guidelines for human resource managers in the hotel industry to reduce burnout and increase organizational commitment of employees. This study has several limitations. Since this study applied in hospitality industry, it can be limitation of the study. Therefore, future research can examine tourism service settings such as travel agencies and airlines. Moreover, future studies could work other industries such as schools, hospitals.

\section{References}

Angle, H., \& Perry (1981). An empirical assessment of organizational commitment and organizational effectiveness. Administrative Science Quarterly, 26(1), 1-14.

Aven, F., Parker, B., \& McEvoy, G. (1993). Gender and attitudinal commitment to organizations: a metaanalysis. Journal of Business Research, 26(1), 63-73.

Bateman, T. S., \& Stresser, S. (1984). A longitudinal analysis of the antecedents of organizational commitment. Academy of Management Journal, 27(1), 95-112.

Burrell, J., Manfredi, S., Rollin, H., Price, L., \& Stead, L. (1997). Equal opportunities for women employees in the hospitality industry: a comparison between France, Italy, Spain and the UK. International Journal of Hospitality Management, 16(2), 161-179.

Casal, J. (1996). Shoot for the 'stars'. Hospitals should hire worker types most likely to satisfy patients. Journal of Health Care Marketing, 16(2), 22-26.

Chiang, C. F., \& Liu, B. Z. (2017). Examining job stress and burnout of hotel room attendants: internal marketing and organizational commitment as moderators. Journal of Human Resources in Hospitality \& Tourism, 16(4), 367-383.

Cook, J., \& Wall, T. (1980). New work attitude measures of trust, organizational commitment and personal need non-fulfilment. Journal of Occupational Psychology, 53(1), 39-52.

Fulford, M. D. (2005). That's not fair! The test of a model of organizational justice, job satisfaction, and organizational commitment among hotel employees. Journal of Human Resources in Hospitality $\mathcal{E}$ Tourism, 4(1), 73-84.

Gemlik, N., Sisman, F. A., \& Sigri, U. (2010). The relationship between burnout and organizational commitment among health sector staff in Turkey. Journal of Global Strategic Management, 8, 137149.985.

Halbesleben, J. R., \& Buckley, M. R. (2004). Burnout in organizational life. Journal of Management, 30(6), 859879.

Hau-siu Chow, I. (1994). Organizational commitment and career development of Chinese managers in Hong Kong and Taiwan. International Journal of Career Management, 6(4), 3-9.

Hollet-Haudebert, S., Mulki, J. P., \& Fournier, C. (2011). Neglected burnout dimensions: Effect of depersonalization and personal nonaccomplishment on organizational commitment of sales people. Journal of Personal Selling \& Sales Management, 31(4), 411-428.

Humborstad, S., Humborstad, B., Whitfield, R. (2007). Burnout and service employees' willingness to deliver quality service. Journal of Human Resources in Hospitality \& Tourism, 7(1), 45-64.

Jackson, S. E., \& Schuler, R. S. (1982). Preventing employee burnout. Personnel, 60(2), 58-68. 
Jackson, S. E., Turner, J. A., \& Brief, A. P. (1987). Correlates of burnout among public service lawyers. Journal of Organizational Behavior, 8(4), 339-349.

Jung, J., \& Kim, Y. (2012). Causes of newspaper firm employee burnout in Korea and its impact on organizational commitment and turnover intention. The International Journal of Human Resource Management, 23(17), 3636-3651.

Jung, H. S., Yoon, H. H., \& Kim, Y. J. (2012). Effects of culinary employees' role stress on burnout and turnover intention in hotel industry: moderating effects on employees' tenure. The Service Industries Journal, 32(13), 2145-2165.

Kalliath, T. J., O'driscoll, M. P., \& Gillespie, D. F. (1998). The relationship between burnout and organizational commitment in two samples of health professionals. Work \& Stress, 12(2), 179-185.

Kim, S. Y., Kim, J. K., \& Park, K. O. (2013). Path analysis for workplace incivility, empowerment, burnout, and organizational commitment of hospital nurses. Journal of Korean Academy of Nursing Administration, 19 (5), 555-564.

Koch, J. L., \& Steers, R. M. (1978). Job attachment, satisfaction, and turnover among public sector employees. Journal of Vocational Behavior, 12(1), 119-128.

Koyuncu, M., Fiksenbaum, L., Burke, R. J., \& Demirer, H. (2008). Predictors of commitment to careers in the tourism industry. Anatolia, 19(2), 225-236.

Kuruuzum, A., Anafarta, N., \& Irmak, S. (2008). Predictors of burnout among middle managers in the Turkish hospitality industry. International Journal of Contemporary Hospitality Management, 20(2), 186198.

Ledgerwood, C. E., Crotts, J. C., \& Everett, A. M. (1998). Antecedents of employee burnout in the hotel industry. Progress in Tourism and Hospitality Research, 4(1), 31-44.

Lee, R. T., \& Ashforth, B. E. (1996). A meta-analytic examination of the correlates of the three dimensions of job burnout. Journal of Applied Psychology, 81(2), 123.

Lee, K.E., \& Shin, K.H. (2005), Job burnout, engagement and turnover intention of dieticians and chefs at a contract foodservice management company. Journal of Community Nutrition, 7(2), 100-106.

Leiter, M. P., \& Maslach, C. (1988). The impact of interpersonal environment on burnout and organizational commitment. Journal of Organizational Behavior, 9(4), 297-308.

Liang, Y. W. (2012). The relationships among work values, burnout, and organizational citizenship behaviors: A study from hotel front-line service employees in Taiwan. International Journal of Contemporary Hospitality Management, 24(2), 251-268.

Loke C. (2001). Leadership behaviours: effects on job satisfaction, productivity and organizational commitment. Journal of Nursing Management, 9(4), 191-204.

Maslach, C., \& Jackson, S. E. (1981). The measurement of experienced burnout. Journal of Organizational Behavior, 2(2), 99-113.

Maslach, C., Schaufeli, W. B., \& Leiter, M. P. (2001). Job burnout. Annual Review of Psychology, 52(1), 397-422.

Mathieu, J. E., \& Zajac, D. M. (1990). Review and meta-analysis of the antecedents, correlates, and consequences of organizational commitment. Psychological Bulletin, 108(2), 171-194.

Maxwell, G., \& Steele, G. (2003). Organisational commitment: a study of managers in hotels. International Journal of Contemporary Hospitality Management, 15(7), 362-369.

Ministry of Culture and Tourism. (1989). Hotel and Tourism Industry Labor Force Survey. Ankara: Ministry of Culture and Tourism.

Ministry of Culture and Tourism. (2009). Tourism Statistics. Retrieved from http://www.kultur.gov.tr/TR/belge/1-63779/turizm-belgeli-tesisler.html 
Mowday, R. T., Steers, R. M., \& Porter, L. W. (1979). The measurement of organizational commitment. Journal of Vocational Behavior, 14(2), 224-247.

Nagar, K. (2012). Organizational commitment and job satisfaction among teachers during times of burnout. Vikalpa, 37(2), 43-60.

Perrewé, P.L., Brymer, R.A., Stepina, L.P. and Hassell, B.L. (1991). A causal model examining the effects of age discrimination on employee psychological reactions and subsequent turnover intentions. International Journal of Hospitality Management, 10(3), 245-60.

Peng, J., Jiang, X., Zhang, J., Xiao, R., Song, Y., Feng, X., Zhang, Y., \& Miao, D. (2013). The impact of psychological capital on job burnout of Chinese nurses: The mediator role of organizational commitment. Plos/one, 8(12), e84193.

Salehi, M., \& Gholtash, A. (2011). The relationship between job satisfaction, job burnout and organizational commitment with the organizational citizenship behavior among members of faculty in the Islamic Azad University-first district branches, in order to provide the appropriate model. Procedia-Social and Behavioral Sciences, 15, 306-310.

Smith, K., Gregory, S. R., \& Cannon, D. (1996). Becoming an employer of choice: Assessing commitment in the hospitality workplace. International Journal of Contemporary Hospitality Management, 8(6), 3-9.

Wagner, C. M. (2007). Organizational commitment as a predictor variable in nursing turnover research: literature review. Journal of Advanced Nursing, 60(3), 235-247

Yamane, T. (2001). Temel Ornekleme Yontemleri. In M. Alptekin Esin, Celal Aydin Akif Bakir, \& Gurbuzsel Esen (Eds.), First ed., 116-117. Istanbul: Literatur Yayincilik.

Yavas, U., Karatepe, O. M., \& Babakus, E. (2011). Interrole conflicts in the hospitality industry: The role of positive affectivity as an antidote. Hospitality Review, 29(2), 6.

Yousef, D. A. (2002). Job satisfaction as a mediator of the relationship between role stressors and organizational commitment: A study from an Arabic cultural perspective. Journal of Managerial Psychology, 17(4), 250-266. 